\title{
Preparation and Properties of Molecular Composite Films of Block Copolyimides Based on Rigid Rod and Semi-Flexible Segments
}

\author{
Yoshiyuki OISHI, Kazuo ITOYA, Masa-aki KAKIMOTO, \\ and Yoshio IMAI* \\ Department of Organic and Polymeric Materials, Tokyo Institute of Technology, \\ Ookayama, Meguro-ku, Tokyo 152, Japan
}

(Received February 27, 1989)

\begin{abstract}
Molecular composite films of block copolyimides consisting of semi-flexible poly- $N, N^{\prime}$-(oxydi- $p$-phenylene)pyromellitimide (PIOD) and rigid-rod poly- $N, N^{\prime}$-( $p$-phenylene)pyromellitimide were prepared by the usual two step ring-opening polyaddition and subsequent thermal imidization method, starting from pyromellitic dianhydride and either the aromatic diamines or their $N$-trimethylsilyl-substituted derivatives. The block copolyimide films were transparent and yellow in color over the whole composition ranges, and changed from brittle to ductile films with increasing PIOD content. As the PIOD content increased, the tensile modulus decreased monotonically, while the elongation at break and fracture energy increased in a similar fashion. The behavior of the tensile strength, however, was rather complicated.
\end{abstract}

KEY WORDS Molecular Composite Films / Block Copolyimides / Rigid Rod Polyimide / Semi-Flexible Polyimide / $N$-Silylated Diamine Method / Tensile Properties /

Currently there is increasing interest in molecular composites. ${ }^{1-3} \mathrm{~A}$ molecular composite is defined as a polymeric material consisting of a rigid rod polymer molecularly dispersed in a random coil polymer matrix. This is expected to have a higher modulus and greater strength than a macroscopic composite because of the high aspect ratio (aspect ratio $=$ length/ diameter) of a rigid rod polymer molecule. Although an approach to molecular composites via physical blending has been extensively studied, ${ }^{4}$ the main problem often encountered is that the rigid rod molecule aggregates in solution at the expense of the random coil matrix material. A solution to this problem is to chemically connect the rigid rod molecules and the random coil polymers together in a block copolymer. However, little is known about this type of molecular composites. $^{1,2,5}$
Aromatic polyimides are known as the most important family of high temperature polymers during the past three decades, ${ }^{6}$ and have been used for high performance applications in many fields. ${ }^{7,8}$ In particular, the "Kapton" film composed of poly- $N, N^{\prime}$ (oxydi-p-phenylene)pyromellitimide has been used widely for many years, while rigid rod poly- $N, N^{\prime}$-( $p$-phenylene)pyrromellitimide did not afford a useful film because of its high crystallinity. Quite recently, Mita and his group have reported the successful preparation of a high-strength and high-modulus molecular composite film via the physical blending of a rigid polyimide and a flexible polyimide based on $3,3^{\prime}, 4,4^{\prime}$-biphenyltetracarboxylic dianhydride. ${ }^{9}$

We have recently reported the synthesis of high molecular weight polyimides starting from $N$-trimethylsilyl-substituted aromatic di- 
amines in place of the parent aromatic diamines coupled with aromatic tetracarboxylic dianhydrides. ${ }^{10,11}$ One of the advantages of the $N$-silylated diamine method is that the processability of polyimide films via solution casting is greatly improved, probably due to the disturbance of crystallization by the existence of the bulky trimethylsilyl groups along the polymer backbone.

The present study was undertaken to elucidate the nature of the block copolyimidetype molecular composite films. This article describes the preparation of random and block copolyimides consisting of semi-flexible poly$N, N^{\prime}$-(oxydi-p-phenylene)pyromellitimide (PIOD) and rigid rod poly- $N, N^{\prime}-(p$-phenylene)pyromellitimide (PIPD) by adopting both the diamine method and the $N$-silylated diamine method, and the evaluation of thermal and tensile properties of the obtained copolyimide films.

\section{EXPERIMENTAL}

\section{Materials}

Pyromellitic dianhydride (PMDA) was purified by vacuum sublimation. Bis(4-aminophenyl) ether (ODA) and $p$-phenylenediamine were purified by recrystallization from tetrahydrofuran and by vacuum distillation, respectively. $N, N^{\prime}$-Bis(trimethylsilyl)bis(4aminophenyl) ether (SiODA) and $N, N^{\prime}$-bis(trimethylsilyl)-p-phenylenediamine (SiPPDA) were prepared according to the method reported elsewhere ${ }^{12}$ by the reaction of the corresponding diamines with trimethylsilyl chloride in the presence of triethylamine in dry toluene. $N, N$-Dimethylacetamide (DMAc) was purified by vacuum distillation over calcium hydride.

\section{Preparation of Copolyimide Films}

In this article, we designate the random and block copolyimides as " $R$ " and " $B$ ", respectively, and the copolymers prepared by the $N$ silylated diamine method as "Si". Within the block copolyimides, the letter $x$ represents the degree of polymerization of the PIOD oligomer and $y$ represents that of the PIPD oligomer, before the block copolyimide was obtained. They varied between 2.5 and 40 . The following numerical number simply denotes the PIOD content $\times 10^{-1}$. For instance, the copolymer SiBx8 means the block copolymers obtained by the $N$-silylated diamine method having the PIOD content of $84 \mathrm{wt} \%$ while $y$ of the PIPD oligomer was kept 10 . Two typical examples of the preparation of copolyimide films are given below.

Random copolymer SiR8 Film by the OneStep Procedure. To a solution of $1.378 \mathrm{~g}$ $(4.0 \mathrm{mmol})$ of SiODA and $0.252 \mathrm{~g}(1.0 \mathrm{mmol})$ of SiPPDA in $20 \mathrm{ml}$ of DMAc were added $1.09 \mathrm{~g}(5.0 \mathrm{mmol})$ of solid PMDA all at once, and the mixture was stirred at $0^{\circ} \mathrm{C}$ for $30 \mathrm{~min}$ in a nitrogen atmosphere. Then the stirring was continued at $20-25^{\circ} \mathrm{C}$ for $6 \mathrm{~h}$. During this period, a highly viscous solution which was difficult to stir was obtained, and the solution was diluted with 5-15 $\mathrm{ml}$ of DMAc for efficient stirring. The polyamic acid solution just prepared was cast onto a glass plate, and dried at room temperature for $24 \mathrm{~h}$ under vacuum. Thermal imidization of the film cast on the glass plate was accomplished by sequential $1 \mathrm{~h}$ heating each at 80,220 , and $280^{\circ} \mathrm{C}$, under high vacuum. The imidized film was removed from the glass plate and used for further measurements. A small portion of the polymer solution was also poured into methanol, and the precipitated polyamic acid was collected and dried at room temperature for $12 \mathrm{~h}$ under high vacuum for the purpose of viscosity measurements.

Block Copolymer SiBx8 Film by the Two-Pot Procedure. In a flask, $0.894 \mathrm{~g}(4.1 \mathrm{mmol})$ of PMDA was added to a solution of $1.378 \mathrm{~g}$ $(4.0 \mathrm{mmol})$ of SiODA in $15 \mathrm{ml}$ of DMAc, and the mixture was stirred at $0^{\circ} \mathrm{C}$ for $30 \mathrm{~min}$ and then at $20-25^{\circ} \mathrm{C}$ for $1 \mathrm{~h}$ under nitrogen. In another flask, $0.196 \mathrm{~g}(0.9 \mathrm{mmol})$ of PMDA was reacted with $0.252 \mathrm{~g} 1.0 \mathrm{mmol}$ ) of SiPPDA 
in $5 \mathrm{ml}$ of DMAc under the same reaction conditions. After that, two polymer solutions just formed were combined in one flask, and the mixture was stirred at $20-25^{\circ} \mathrm{C}$ for another $5 \mathrm{~h}$ under nitrogen, giving a viscous solution of resulting block copolyamic acid. The film preparation and work-up were the same as those described in the preceding experiment.

\section{Measurements}

Thermogravimetry (TG) was performed with a Shimadzu thermal analyzer TGA-30M. Tensile properties were determined from the stress-strain curves obtained with a Toyo Baldwin Tensilon UTM-III at a strain rate of $10 \mathrm{~mm} \mathrm{~min}^{-1}$ at room temperature. Measurements were performed with film specimens $(5.0 \mathrm{~cm}$ of gauge length, $1.0 \mathrm{~cm}$ wide, and $0.1 \mathrm{~mm}$ thick), and the data of the specimen that afforded the highest elongation at break, after five individual determinations, were taken.

\section{RESULTS AND DISCUSSION}

\section{Preparation of Copolyimide Films}

Aromatic polyimides have been prepared conventionally by the ring-opening polyaddition of aromatic diamines to aromatic tetracarboxylic dianhydrides in amide solvents such as DMAc giving precursor polyamic acids, followed by thermal imidization. ${ }^{6}$ An alternate route for the synthesis of polyimides is that starting from $N$-trimethylsilyl-substituted aromatic diamines and tetracarboxylic dianhydrides. ${ }^{10,11}$ These techniques were applied to the preparation of random and block copolyimide films.

The random copolyimides of $\mathrm{R}$ - and SiRseries were synthesized by a one-step procedure. Thus all the reactants, PMDA, ODA, and PPDA (or SiODA and SiPPDA), were reacted all together in DMAc at room temperature affording random copolyamic acids (or their trimethylsilyl esters), which in turn were converted to random copolyimides in the form of films (eq. 1). The homopolyamic acids and the corresponding homopolyimides, PIOD and PIPD, were also obtained in a same manner starting from ODA and PPDA, respectively, coupled with PMDA. Table I summarizes the results of the random copolymerizations.

The block copolyimides of B- and SiB-series

Table I. Preparation of random copolyamic acids and their copolyimides ${ }^{\mathrm{a}}$

\begin{tabular}{|c|c|c|c|c|c|c|c|}
\hline & & & & \multicolumn{4}{|c|}{ Random copolymer } \\
\hline \multicolumn{2}{|c|}{$\begin{array}{c}\text { Random } \\
\text { composition }\end{array}$} & \multirow{3}{*}{$\begin{array}{l}\text { ODA/PPDA } \\
\text { in feed } \\
\mathrm{mmol} / \mathrm{mmol}\end{array}$} & \multirow{3}{*}{$\begin{array}{c}\begin{array}{c}\text { PIOD } \\
\text { content }\end{array} \\
\mathrm{wt} \%\end{array}$} & \multicolumn{2}{|c|}{ R-Series } & \multicolumn{2}{|c|}{ SiR-Series } \\
\hline \multirow{2}{*}{$x$} & \multirow{2}{*}{$y$} & & & \multirow{2}{*}{ Code $^{c}$} & $\eta_{\text {inh }}^{d}$ & \multirow{2}{*}{ Code $^{\mathrm{c}}$} & \multirow{2}{*}{$\eta_{\text {inh }}{ }^{\mathrm{d}}$} \\
\hline & & & & & $\mathrm{dlg}^{-1}$ & & \\
\hline 100 & 0 & $5.0 / 0$ & 100 & PIOD & 1.86 & SiPIOD & 1.90 \\
\hline 80 & 20 & $4.0 / 1.0$ & 84 & R8 & 2.31 & SiR8 & 1.63 \\
\hline 60 & 40 & $3.0 / 2.0$ & 66 & R6 & 1.41 & SiR6 & 2.15 \\
\hline 40 & 60 & $2.0 / 3.0$ & 46 & R4 & 1.89 & $\mathrm{SiR} 4$ & 1.47 \\
\hline 20 & 80 & $1.0 / 4.0$ & 24 & $\mathbf{R} 2$ & 2.17 & $\mathrm{SiR} 2$ & 1.13 \\
\hline 0 & 100 & $0 / 5.0$ & 0 & PIPD & 1.34 & SiPIPD & 1.14 \\
\hline \multicolumn{8}{|c|}{$\begin{array}{l}\text { Polymerization was carried out with } 5.0 \mathrm{mmol} \text { of PMDA and } 5.0 \mathrm{mmol} \text { of a mixture of OD } \\
\text { and SiPPDA) in } 20 \mathrm{ml} \text { of DMAc at } 0^{\circ} \mathrm{C} \text { for } 30 \mathrm{~min} \text { and at } 20-25^{\circ} \mathrm{C} \text { for } 6 \mathrm{~h} \text { in nitrogen. } \\
\text { b [PIOD weight]/[PIOD weight }+ \text { PIPD weight] in feed. } \\
\text { c Code of homo- and copolyimides. }\end{array}$} \\
\hline
\end{tabular}




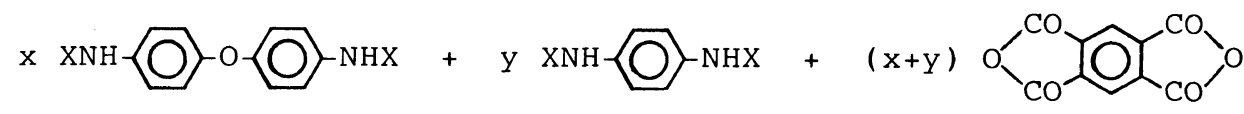

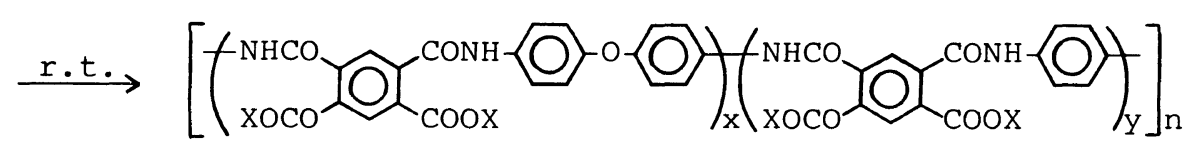

$$
\begin{aligned}
& \text { Random Precursors }
\end{aligned}
$$

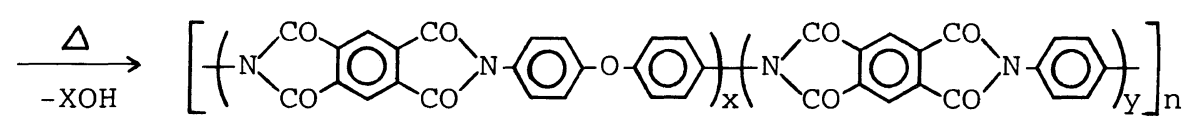

$$
\begin{aligned}
& \text { Random Copolyimides }
\end{aligned}
$$

$$
\begin{aligned}
& x \mathrm{xNH}-\mathrm{O}-\mathrm{O}-\mathrm{NHx}+(\mathrm{x}+1) \text { O }
\end{aligned}
$$

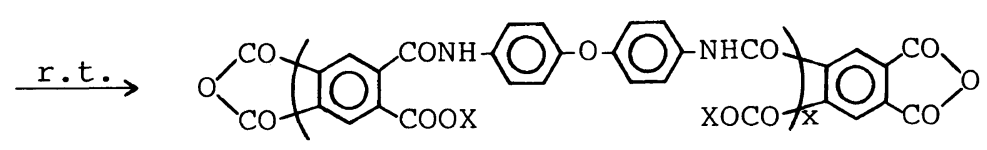

$$
\begin{aligned}
& \text { I } \\
& \mathrm{y} x \mathrm{xNH}-\mathrm{NHX}+(\mathrm{y}-1) \mathrm{O}_{\mathrm{CO}}^{\mathrm{CO}} \widehat{\mathrm{O}}_{\mathrm{CO}}^{\mathrm{CO}} \\
& \left.\stackrel{\mathrm{r.t.}}{\longrightarrow} \mathrm{xNH}-\mathrm{O}\left(\mathrm{xOCO}_{\mathrm{COOX}}^{\mathrm{NHCO}}\right)_{y-1}^{\mathrm{CONH}}-\mathrm{O}\right)_{\mathrm{NHX}}^{\mathrm{NHX}} \\
& \text { II } \\
& \text { I }+ \text { II } \stackrel{\text { r.t. }}{\longrightarrow} \text { Block Precursors } \\
& \underset{-\mathrm{XOH}}{\stackrel{\Delta}{\longrightarrow}} \text { Block Copolyimides } \\
& \mathrm{X}: \mathrm{H}, \mathrm{Si}\left(\mathrm{CH}_{3}\right)_{3}
\end{aligned}
$$

were synthesized by the two-pot procedure (eq. calculated excess of PMDA in DMAc. In 2 ). In one pot, $\alpha, \omega$-dianhydride-terminated another pot, $\alpha, \omega$-diamine-terminated polypolyamic acid oligomers having average de- amic acid oligomers with average degree of gree of polymerization $(x)$ of $2.5-40$ were polymerization $(y)$ of $2.5-40$ were synthesized prepared by the reaction of ODA with a from a calculated excess of PPDA with PMDA 
Table II. Preparation of block copolyamic acids and their copolyimides ${ }^{\mathrm{a}}$

\begin{tabular}{|c|c|c|c|c|c|c|c|c|c|c|}
\hline & & & & \multirow{2}{*}{\multicolumn{2}{|c|}{ Monomers in feed }} & \multirow{4}{*}{$\frac{\begin{array}{c}\text { PIOD } \\
\text { content }^{\mathrm{b}}\end{array}}{\mathrm{wt} \%}$} & \multicolumn{4}{|c|}{ Block copolymer } \\
\hline \multicolumn{4}{|c|}{ Block composition } & & & & \multicolumn{2}{|c|}{ B-Series } & \multicolumn{2}{|c|}{ SiB-Series } \\
\hline \multirow[t]{2}{*}{$x$} & \multirow[t]{2}{*}{$y$} & \multirow{2}{*}{ PIOD } & \multirow{2}{*}{ PIPD } & \multicolumn{2}{|c|}{$\mathrm{mmol} / \mathrm{mmol}$} & & \multirow[b]{2}{*}{ Code $^{c}$} & \multirow{2}{*}{$\frac{\eta_{\mathrm{inh}}^{\mathrm{d}}}{\mathrm{dl} \mathrm{g}^{-1}}$} & \multirow[b]{2}{*}{ Code $^{\mathfrak{c}}$} & \multirow{2}{*}{$\frac{\eta_{\mathrm{inh}}^{\mathrm{d}}}{\mathrm{dl} 1^{-1}}$} \\
\hline & & & & PMDA/ODA & PPDA/PMDA & & & & & \\
\hline 40 & 10 & 15280 & 2900 & $4.1 / 4.0$ & $1.0 / 0.9$ & 84 & $\mathrm{Bx} 8$ & 2.26 & $\mathrm{SiB} \times 8$ & 1.90 \\
\hline 15 & 10 & 5730 & 2900 & $3.2 / 3.0$ & $2.0 / 1.8$ & 66 & Bx6 & 1.96 & $\mathrm{SiBx} 6$ & 1.82 \\
\hline 6.7 & 10 & 2520 & 2900 & $2.3 / 2.0$ & $3.0 / 2.7$ & 46 & $\mathrm{Bx} 4$ & 1.60 & $\mathrm{SiBx} 4$ & 1.69 \\
\hline 2.5 & 10 & 955 & 2900 & $1.4 / 1.0$ & $4.0 / 3.6$ & 24 & $\mathrm{~B} \times 2$ & 1.05 & $\mathrm{SiB} \times 2$ & 1.69 \\
\hline 10 & 2.5 & 3820 & 725 & $3.6 / 4.0$ & $1.0 / 1.4$ & 84 & By8 & 1.01 & SiBy8 & 1.41 \\
\hline 10 & 6.7 & 3820 & 1915 & $2.7 / 3.0$ & $2.0 / 2.3$ & 66 & By6 & 1.25 & SiBy6 & 1.60 \\
\hline 10 & 15 & 3820 & 4350 & $1.8 / 2.0$ & $3.0 / 3.2$ & 46 & By4 & 1.62 & SiBy4 & 1.06 \\
\hline 10 & 40 & 3820 & 11600 & $0.9 / 1.0$ & $4.0 / 4.1$ & 24 & By2 & 1.78 & SiBy2 & 1.01 \\
\hline
\end{tabular}

a A polymer solution prepared from a mixture of PMDA and ODA (or SiODA) in DMAc, and another polymer solution from PMDA and PPDA (or SiPPDA) in DMAc were combined, and the polymerization was carried out at $20-25^{\circ} \mathrm{C}$ for $5 \mathrm{~h}$ in nitrogen.

b [PIOD weight]/[PIOD weight + PIPD weight] in feed.

c Code of copolyimides.

${ }^{d}$ Inherent viscosity of polyamic acid, measured at a concentration of $0.5 \mathrm{~g} \mathrm{dl}^{-1}$ in DMAc at $30^{\circ} \mathrm{C}$.

in DMAc. After that, the preformed $\alpha, \omega$ dianhydride-terminated oligomer solution was added to the $\dot{\alpha}, \omega$-diamine-terminated oligomer solution, and they were reacted with each other affording the B-series block copolyamic acids and the corresponding copolyimides. The SiB-series block copolymers were prepared in the same fashion by using the $N$ trimethylsilyl substituted diamines, SiODA and SiPPDA, in place of the parent aromatic diamines.

In the $\mathrm{Bx}$ - and $\mathrm{SiBx}$-series block copolyimides, the number-average molecular weight $\left(\bar{M}_{n}\right)$ of the PIPD oligomer was kept constant ( $\left.y=10, \bar{M}_{n}=2,900\right)$, and the $\bar{M}_{n}$ s of the PIOD oligomers were varied from 960 to $15,300(x=2.5-40)$ in four steps. On the other hand, the By- and SiBy-series block copolymers, the $\bar{M}_{n}$ of the PIOD oligomer was held constant $\left(x=10, \bar{M}_{n}=3,800\right)$, and the $\bar{M}_{n}$ s of the PIPD oligomers were changed from 730 to $11,600(y=2.5-40)$. Table II summarizes the results of the block copolymerizations.
All the random and block copolyamic acids obtained had inherent viscosities of over 1.0 $\mathrm{dl} \mathrm{g}^{-1}$. The viscosity values were high enough to produce block copolyimide films with wellbalanced tensile properties. ${ }^{13}$ All the copolyimide films prepared from the corresponding copolyamic acids were transparent and yellow in color over the whole composition ranges, irrespective to the synthetic methods. This transparency suggests that two polyimide components, PIOD and PIPD, were well mixed on the molecular level via the copolymerizations, giving molecular composite films.

\section{Thermal Properties of Copolyimide Films}

The thermal decomposition behavior of the copolyimides was evaluated by means of TG in a nitrogen atmosphere, and the decomposition temperature $(10 \%$ weight loss temperature) is summarized in Table III. All the copolyimides are highly thermally stable and did not lose weight below $450^{\circ} \mathrm{C}$ under nitrogen. The decomposition temperatures ranged from $580^{\circ} \mathrm{C}$ 
Table III. Thermal decomposition behavior of random and block copolyimides ${ }^{\mathrm{a}}$

\begin{tabular}{cllllll}
\hline \multirow{2}{*}{$\begin{array}{c}\text { PIOD } \\
\text { content }\end{array}$} & \multicolumn{6}{c}{ Block copolymer } \\
\cline { 4 - 7 } & R- & SiR- & Bx- & By- & SiBx- & SiBy- \\
wt \% & Series & Series & Series & Series & Series & Series \\
\hline 100 & 585 & 585 & - & - & - & - \\
84 & 595 & 595 & 585 & 590 & 580 & 595 \\
66 & 600 & 590 & 585 & 585 & 580 & 590 \\
46 & 610 & 595 & 590 & 590 & 590 & 590 \\
24 & 615 & 605 & 590 & 595 & 600 & 605 \\
0 & 610 & 610 & - & - & - & - \\
\hline
\end{tabular}

${ }^{a}$ A $10 \%$ weight loss temperature determined by $\mathrm{TG}$ at a heating rate of $10^{\circ} \mathrm{C} \mathrm{cm}^{-1}$ in nitrogen.

to $615^{\circ} \mathrm{C}$, and rose gradually with decreasing PIOD content. No appreciable differences in the decomposition temperatures were observed between the random copolymers ( $\mathrm{R}$ - and $\mathrm{SiR}$-series) and the block copolymers (Bx-, By-, $\mathrm{SiBx}$-, and $\mathrm{SiBy}$-series), and even between the copolymers obtained by the conventional diamine method (R-, Bx-, and By-series) and those by the $N$-silylated diamine method (SiR-, $\mathrm{SiBx}-$, and SiBy-series).

\section{Tensile Properties of Copolyimide Films}

The tensile properties of the copolyimide films were evaluated from the stress-strain curves, and are summarized in Table IV. The tensile values, tensile strength $(T)$ /elongation at break $(E) /$ tensile modulus $(M)$, of the PIOD homopolyimide film, prepared either by the diamine method or by the $N$-silylated diamine method, were about $150 \mathrm{MPa} / 90 \% / 2.0 \mathrm{GPa}$, and these values are essentially in agreement with the $\mathrm{T} / \mathrm{E} / \mathrm{M}$ values of $170 \mathrm{MPa} / 70 \% / 3.0$ GPa for "Kapton", a commercial polyimide film produced by du Pont. On the other hand, the PIPD homopolyimide obtained by either of the two methods did not afford good quality film, which was extremely brittle with $\mathrm{T} / \mathrm{E} / \mathrm{M}$ values of only $15 \mathrm{MPa} / 3 \% / 2.5 \mathrm{GPa}$.

Figure 1 gives typical examples of the stressstrain curves for films of the R-series random copolyimides with varying PIOD content. The
Table IV. Tensile properties of copolyimide films

\begin{tabular}{|c|c|c|c|c|}
\hline Block & $\begin{array}{l}\text { Tensile } \\
\text { strength }\end{array}$ & $\begin{array}{c}\text { Elongation } \\
\text { at break }\end{array}$ & $\begin{array}{l}\text { Tensile } \\
\text { modulus }\end{array}$ & $\begin{array}{c}\text { Fracture } \\
\text { energy }\end{array}$ \\
\hline & $\mathrm{MPa}$ & $\%$ & $\mathrm{GPa}$ & $\mathrm{MJ} \mathrm{m}^{-1}$ \\
\hline PIOD & 146 & 89 & 2.0 & 97 \\
\hline R8 & 137 & 71 & 2.2 & 74 \\
\hline R6 & 156 & 66 & 2.6 & 68 \\
\hline R4 & 153 & 38 & 3.3 & 46 \\
\hline R2 & 169 & 10 & 4.9 & 12 \\
\hline SiPIOD & 147 & 88 & 2.0 & 94 \\
\hline SiR8 & 153 & 79 & 2.1 & 88 \\
\hline SiR6 & 146 & 63 & 2.7 & 62 \\
\hline SiR4 & 162 & 37 & 3.7 & 50 \\
\hline SiR2 & 156 & 7.0 & 4.9 & 8 \\
\hline Bx 8 & 135 & 62 & 2.6 & 50 \\
\hline Bx6 & 153 & 51 & 3.1 & 54 \\
\hline $\mathrm{Bx} 4$ & 131 & 15 & 3.2 & 15 \\
\hline $\mathrm{Bx} 2$ & 106 & 4.2 & 4.5 & 3 \\
\hline SiBx 8 & 148 & 76 & 2.4 & 60 \\
\hline $\mathrm{SiB} \times 6$ & 182 & 50 & 2.8 & 68 \\
\hline SiBx4 & 163 & 31 & 4.1 & 36 \\
\hline $\mathrm{SiBx} 2$ & 127 & 3.6 & 5.6 & 3 \\
\hline By8 & 115 & 43 & 2.2 & 30 \\
\hline By6 & 119 & 27 & 2.9 & 20 \\
\hline By4 & 135 & 12 & 4.0 & 13 \\
\hline By2 & 89 & 2.4 & 4.9 & 1 \\
\hline SiBy8 & 153 & 71 & 2.2 & 70 \\
\hline SiBy6 & 139 & 43 & 3.1 & 51 \\
\hline SiBy4 & 165 & 26 & 3.7 & 35 \\
\hline SiBy2 & 113 & 3.8 & 5.2 & 3 \\
\hline
\end{tabular}

copolyimide films changed from ductile to brittle films depending markedly on PIOD content. In general, with decreasing PIOD content, in other words, with increasing rigid rod segments, the tensile modulus increased and elongation at break decreased, while the tensile strength increased slightly.

Figure 2 to Figure 5 show the tensile mod ulus, elongation at break, tensile strength, and fracture energy of the copolyimide films as a function of PIOD content. As can be seen from these Figures, the $N$-silylated diamine method affords more uniform copolyimide films having better tensile properties, compared with the films produced by the dimaine method. The method of preparation of the random copolyimide films, i.e., the diamine or $\mathrm{N}$-silyalted diamine method, had little or no 


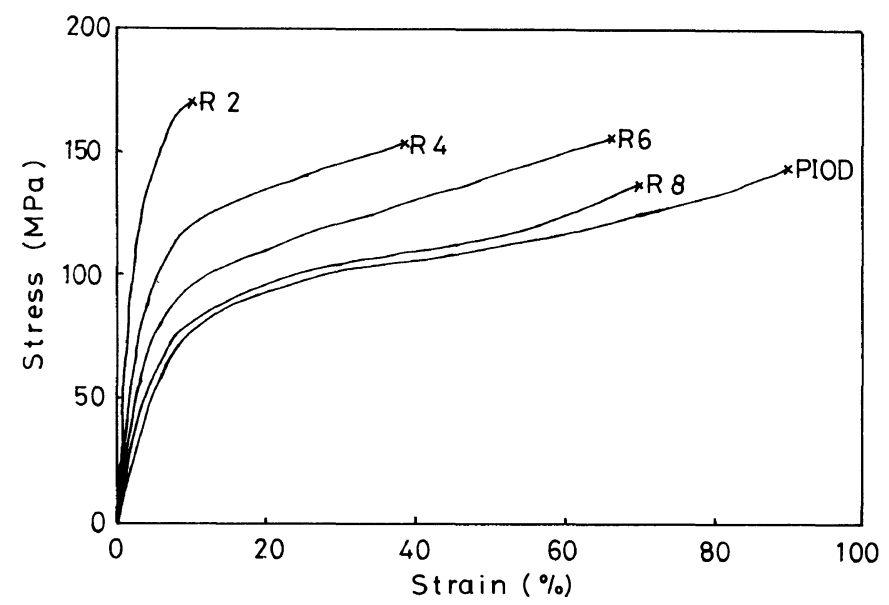

Figure 1. Stress-strain curves for films of R-series random copolyimides.
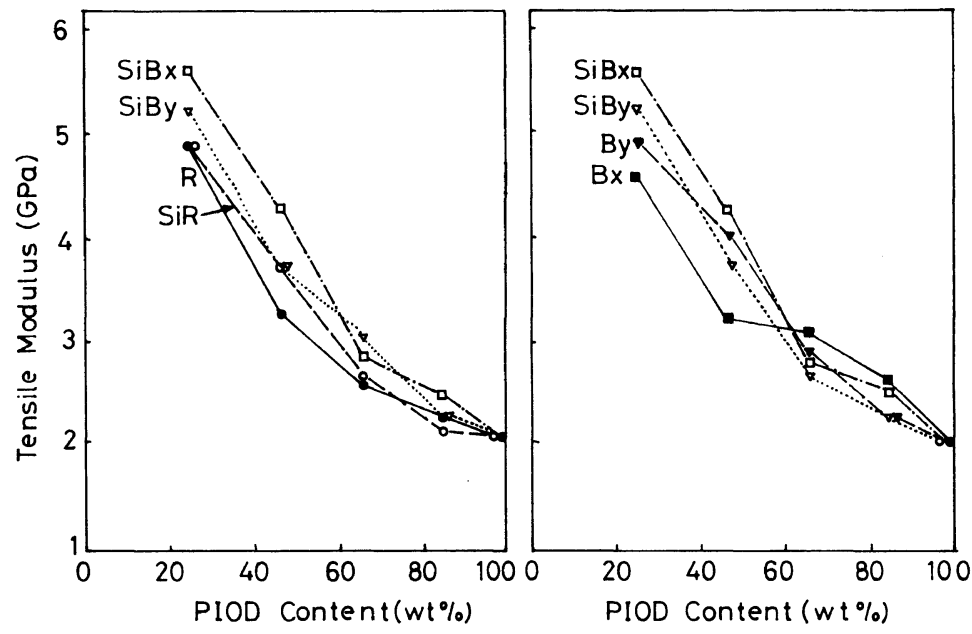

Figure 2. Effect of PIOD content on tensile modulus for films of random and block copolyimides.
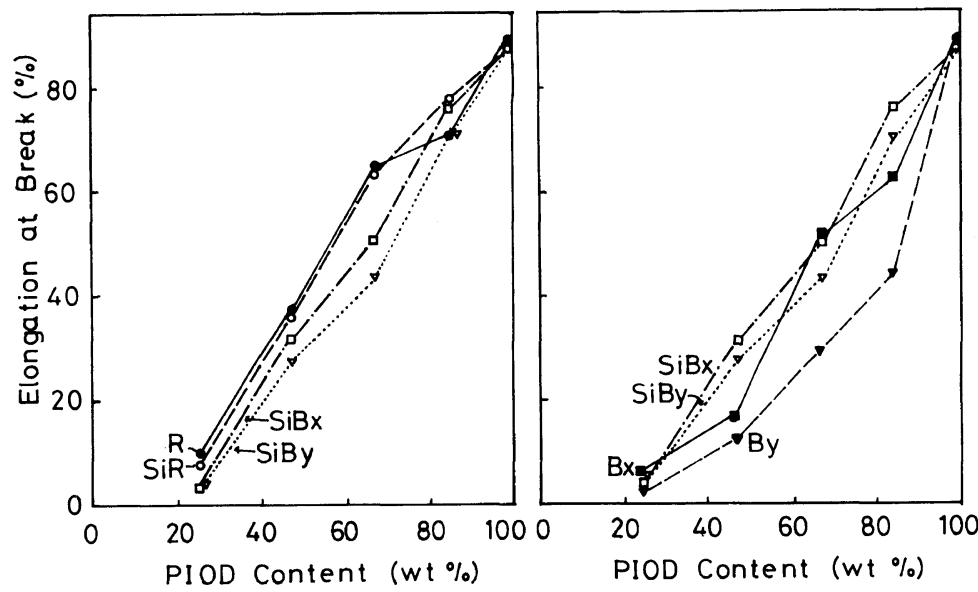

Figure 3. Effect of PIOD content on elongation at break for films of random and block copolyimides. 

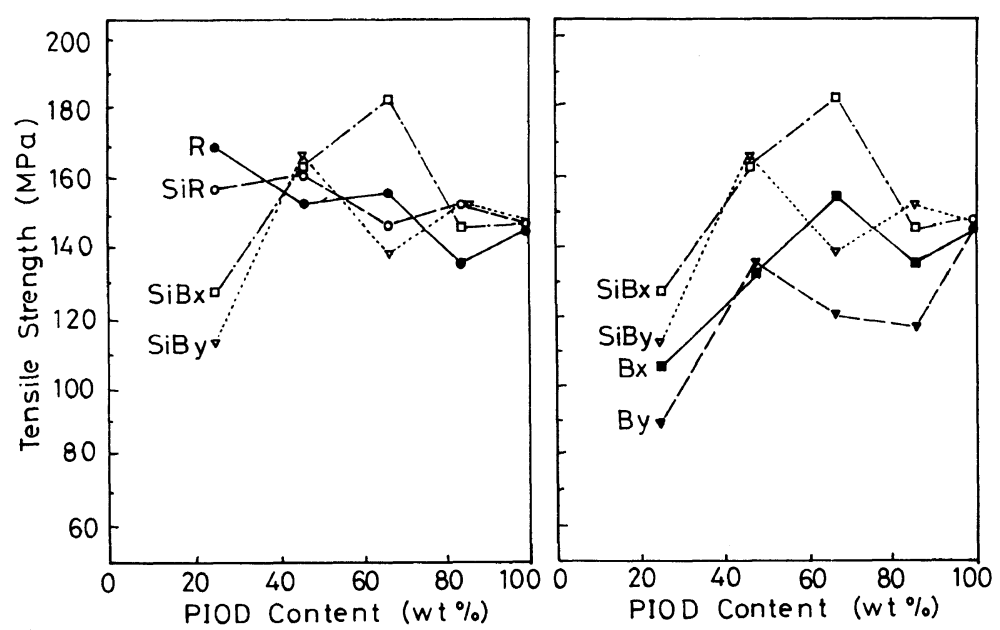

Figure 4. Effect of PIOD content on tensile strength for films of random and block copolyimides.
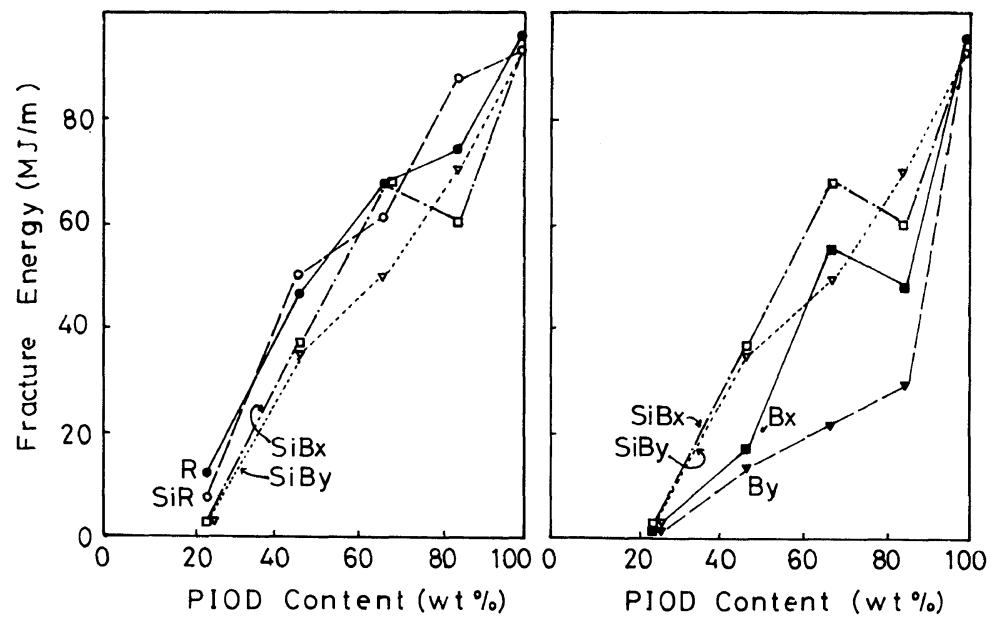

Figure 5. Effect of PIOD content on fracture energy for films of random and block copolyimides.

effect on the film tensile properties. However, the block copolyimide films obtained by the two methods differed appreciably from each other. This is probably attributable to differences in the microstructures between the copolyamic acids and the copolyamic acid trimethylsilyl esters, both copolyimide precursors. Since the copolyamic acid trimethylsilyl esters have bulky trimethylsilyl groups along the polymer backbone, which disrupt the crystallization or phase ordering during the stage of the precursor film formation, the disturbance in the microstructures is fixed as an unequilibrium state and is not repaired during the final stage of thermal imidization to the copolyimide films. As a result, block copolyimide films with better quality are produced, compared with those prepared by the diamine method.

Generally, as PIOD content in the copolyimides increased, the tensile modulus of all the films decreased monotonically, and elongation at break and fracture energy increased in a similar fashion, regardless of the random and block copolyimides or of the synthetic methods. In other words, the films 
lose ductility with increasing rigid rod components. The tensile strength, on the other hand, varied depending on copolyimide composition.

The Elongation at break of the copolyimide films decreased apparently in the order, R-series $>$ Bx-series $>$ By-series copolymers, and SiR-series $>$ SiBx-series $>$ SiBy-series copolymers. Almost the same order was also found for the fracture energy of the copolyimide films. This is quite reasonable, because the fracture energy is highly dependent on elongation at the break.

Although little differences were found in the tensile modulus between the $\mathrm{Bx}$-series and $\mathrm{By}$ series copolyimide films, as well as between the SiBx-series and SiBy-series copolymer films, the tensile modulus of the block copolyimide films was somewhat higher than that of the random copolymer films. These results suggest that the block copolyimide films have a more crystalline nature or a more ordered phase ${ }^{9}$ than the random copolymer films.

The influence of the copolyimide structures (random or block), synthetic methods, and copolymer composition on the tensile strength was rather complicated. The R- and SiR-series random copolyimides afforded films with almost the same tensile strength with each other at a given PIOD content, and the tensile strength tended to decrease slightly with increasing PIOD content.

The behavior of tensile strength of the block copolyimide films is quite different from that of the random copolymer films. Among the block copolyimides, the SiBx-series copolymers afforded films with higher tensile strength than the Bx-series copolymers, and also the SiBy-series than the By-series copolymers. It is of interest that the tensile strength-composition curves for the $\mathrm{Bx}$ - and SiBx-series copolyimide films have a maximum at a PIOD content of $66 \mathrm{wt} \%$, while a maximum was obtained at $46 \mathrm{wt}^{\%} \%$ in the case of By- and SiBy-series copolymer films. This suggests that tensile strength is greatly influenced by the molecular weight of the two copolyimide components, PIOD and PIPD, and the moleuclar weight of 3000 6000 for each component is optimum for the preparation of the block copolyimide films with the highest tensile strength.

In the block copolyimides with a PIOD content of $80 \mathrm{wt} \%$, the aspect ratio of the rigid rod PIOD molecule is low (By8) or the amount of the reinforcing material is comparatively small $(\mathrm{Bx} 8)$, giving films with lower tensile strength. Inversely, the block copolymers with a PIOD content of $20 \mathrm{wt} \%(\mathrm{Bx} 2$ and By 2$)$ also afforded rather brittle films due to the presence of the short matrix molecule. The random copolyimides having a PIOD content of 20 $\mathrm{wt} \%$, however, gave films with better quality, because the long-chain rigid rod portion acts as a reinforcing material and the short-chain portion behaves just as a matrix.

Thus, the molecular composite copolyimide films, which varied from the high-strength film with the $\mathrm{T} / \mathrm{E} / \mathrm{M}$ values of $182 \mathrm{MPa} / 50 \% / 2.8$ $\mathrm{GPa}$ (SiBx6) to the high-modulus film with 156 $\mathrm{MPa} / 7 \% / 4.9 \mathrm{GPa}$ (SiR2), were obtained from combinations of rigid-rod PIPD and semiflexible PIOD via the $N$-silylated diamine method.

Acknowledgments. The authors gratefully acknowledge the support for this research by a Grant-in-Aid for Scientific Research on Priority Areas, New Functionality MaterialsDesign, Preparation, and Control from the Ministry of Education, Science, and Culture of Japan (No. 62604005).

\section{REFERENCES}

1. M. Takayanagi, T. Ogata, M. Morikawa, and T. Kai, J. Macromol. Sci. Phys., B17, 591 (1980).

2. M. Takayanagi, Pure Appl. Chem., 55, 819 (1983).

3. W. F. Hwang, D. R. Wiff, C. L. Benner, and T. E. Helminiak, J. Macromol. Sci. Phys., B22, 231 (1983).

4. R. Yokota, Function Materials, 8[10], 22 (1988).

5. S. J. Krause, T. B. Haddock, G. E. Price, and W. W. Adams, Polymer, 29, 195 (1988).

6. C. E. Sroog, J. Polym. Sci., Macromol. Revs., 11, 161 
(1976).

7. K. L. Mittal, Ed., "Polyimides: Synthesis, Characterization, and Applications," Plenum Press, New York, N. Y., 1984.

8. W. D. Weber and M. R. Gupta, Eds., "Recent Advances in Polyimide Science and Technology," Society Plastic Engineers, Inc., New York, N. Y., 1987.

9. R. Yokota, R. Horiuchi, M.Kochi, H. Soma, and I.
Mita, J. Polym. Sci., Polym. Lett. C, 26, 215 (1988).

10. E. M. Boldebuck and J. F. Klebe, U. S. Patent. 3303157 (1967); Chem. Abstr., 66, 96125f (1967).

11. Y. Oishi, M. Kakimoto, and Y. Imai, 53rd Chem. Soc. Jpn. Fall Meeting Prepr., 26 (1986).

12. Y. Oishi, M. Kakimoto, and Y. Imai, Macromolecules, 21, 547 (1988).

13. W. Volksen, P. Cotts, and D. Y. Yoon, J. Polym. Sci., Polym. Phys. B, 25, 2487 (1987). 